\title{
Incorporation of Indium Tin Oxide Nanoparticles in PEMFC Electrodes
}

\author{
André Wolz,* Susanne Zils, David Ruch, Nicholas Kotov, Christina Roth, and Marc Michel
}

Carbon materials suffer from corrosion at the cathode of polymer electrolyte membrane fuel cells (PEMFCs). In the presence of water, carbon support materials are oxidized to carbon dioxide even at low potentials. Hence, nowadays it is very fashionable to look for alternative support materials, like oxides or conductive polymers. To gain the maximum performance for a new material one should also consider an appropriate electrode structure. This study shows the results for the incorporation of nanosized alternative support materials into advanced electrode architectures. Commercially available indium tin oxide (ITO) nanoparticles ( $<50 \mathrm{~nm}$ ) are used as support for Pt nanoparticles in combination with Nafion-coated multi-walled carbon nanotubes (MWCNTs) on the cathode side of a PEMFC. The MWCNTs promote a high electronic conductivity and help to form a porous network, which could accommodate the Pt/ ITO nanoparticles. The microscopic investigations show a homogeneous electrode structure composed of Pt/ITO and MWCNT/Nafion multilayer. Single cell measurements show a maximum power density of $73 \mathrm{~mW} \mathrm{~cm}{ }^{-2}$ and a Pt utilization of $1468 \mathrm{~mW} \mathrm{mg}_{\mathrm{Pt}}{ }^{-1}$ for the cathode. The performance data and the Pt utilization are comparable to a standard Pt/carbon black electrode possessing the same Pt loading in the electrode. Beside this, it is shown for the first time that ITO serves as support material under real fuel cell conditions.

\section{Introduction}

Polymer electrolyte membrane fuel cells (PEMFCs) are advantageous as energy converters due to their high efficiency without any emission of greenhouse gases during operation. But beside

\section{A. Wolz, Prof. C. Roth}

Renewable Energies Group

Institute for Materials Science

Technische Universitaet Darmstadt

Petersenstr. 23, 64287 Darmstadt, Germany;

E-mail: andre.wolz@tudor.lu

A. Wolz, S. Zils, Dr. D. Ruch, Dr. M. Michel

CRP Henri Tudor

Department of Advanced Materials and Structures

66 rue de Luxembourg, 4002 Esch-sur-Alzette, Luxembourg

Prof. N. Kotov

University of Michigan

Department of Chemical Engineering

2300 Hayward St, Ann Arbor, MI 48109, USA

Prof. C. Roth

Institute for Applied Materials (IAM)-Energy Storage Systems (ESS)

Hermann-von-Helmholtz-Platz 1

76344 Eggenstein-Leopoldshafen, Germany

DOI: 10.1002/aenm.201100711 the ecological advantages, there are also disadvantages to name, which are high costs, low power density compared to batteries, and durability issues. ${ }^{[1]}$ The mentioned points are the main reasons that hinder a general market acceptance in the near future. The unfavorable durability is mainly attributed to corrosion issues in the electrode. The harsh conditions present especially at the cathode side are acidic environment, high oxygen concentration and high water content. These lead to a corrosion of the usually applied high surface carbon support to surface oxides and $\mathrm{CO}_{2}{ }^{[2]}$ and/or a corrosion of the platinum nanoparticles by coarsening mechanisms. ${ }^{[3]}$ The two corrosion mechanisms result in a loss of electrochemical active surface area (ECSA) of the Pt nanoparticles for the oxygen reduction reaction (ORR) with an ongoing decrease in the cell performance. Furthermore, it is known that the carbon oxidation to carbon dioxide is accelerated in the presence of Pt nanoparticles. ${ }^{[4]}$

Platinum is still the most effective catalyst for the hydrogen oxidation and the oxygen reduction reaction in a fuel cell which is hard to replace by an alternative candidate. ${ }^{[5]}$ Therefore, the focus of current research should be on the support material. Many efforts have been made to search for new catalyst supports which are not affected by oxidation in fuel cell environments. In this background, two promising material classes namely conductive polymers $^{[6]}$ and oxides ${ }^{[7]}$ have been identified. Metal oxide catalysts, such as tungsten oxide $\left(\mathrm{WO}_{3}\right)$, have been found to operate via a bi-functional mechanism in the methanol oxidation, ${ }^{[8]}$ and a $\mathrm{Pt} / \mathrm{WO}_{3}$-based electrode showed a twice as high activity towards the oxygen reduction reaction compared to Pt on carbon black in a phosphoric acid fuel cell.[9] For PEMFCs promising candidates are also titanium oxide ${ }^{[10]}$ and tin oxides. ${ }^{[11]}$ Nevertheless, the electric conductivity of semi-conductive oxides has to be improved by implementing oxygen vacancies in a reducing atmosphere or by an appropriate dopant. Doped oxides-antimony tin oxide and indium tin oxide-are well known and used as transparent conductive oxides in many applications like solar cells $^{[12]}$ and displays, ${ }^{[13]}$ and were also considered as support for PEMFCs.

Suffner et al. studied the applicability of antimony doped tin oxide (ATO) as fuel cell catalyst support. ${ }^{[14]}$ It was shown that ATO reached a promising fuel cell performance when 
hollow spheres instead of ATO nanoparticles were used, resulting in an improved electrode structure with enhanced gas permeation.

Indium tin oxide is a mixed oxide of $\mathrm{In}_{2} \mathrm{O}_{3}$ and $\mathrm{SnO}_{2} \cdot \mathrm{In}^{3+}$ is substituted by $\mathrm{Sn}^{4+}$ cations leading to an increased electric conductivity up to $1000 \mathrm{~S} \mathrm{~cm}^{-1}$ as one free electron is provided by each tin atom. ${ }^{[15]}$ It also attracted attention as support material, recently. Chhina et al. used rotating disc and cyclic voltammetry measurements to study the oxidation stability of Pt/ITO compared to Hispec4000 (Alfa Aesar) and $40 \mathrm{wt} \% \mathrm{Pt}$ on Vulcan XC-72 catalyst. ${ }^{[16]}$ They found that Pt/ITO offers a better electrochemical stability with a lower loss of ECSA compared to the carbon supported Pt catalyst, although the Pt nanoparticles had an average size of $13 \mathrm{~nm}$. Park et al. investigated the use of Pt/ ITO for methanol oxidation. ${ }^{[17]}$ They used the glycine nitrate process to deposit Pt particles of the size of $4 \mathrm{~nm}$. The synthesized Pt/ITO nanoparticles possessed a low electrochemical surface area but showed a high activity for methanol oxidation and high oxidation stability in cyclic voltammetry. Both studies investigated the use of ITO as possible fuel cell catalyst support, but the verification of the promising electrochemical characteristics in real single-cell tests is still lacking.

This study focuses on strategies to incorporate Pt/ITO catalyst into an electrode structure in order to give an adequate performance. The choice of another support material than carbon black makes it mandatory to think about the preparation method of the electrode layer and its resulting electrode structure. The nanosized oxide particles have to be assembled differently from the sub-micrometer sized carbon black particles to yield an equally promising structure. The electrode structure is known to have a significant influence on the cell performance. ${ }^{[18]} \mathrm{A}$ homogeneous and porous structure favors the percolation of the reactants and a high accessibility of the Pt nanoparticles results in a high Pt utilization.

Recently, a new assembly technique has been introduced by which it was possible to assemble 1D support materials into 3D networks. ${ }^{[19,20]}$ The networks had a multilayered architecture of polyaniline and carbon nanotubes, both decorated with $\mathrm{Pt}$, and the electrodes reached a 3 times higher Pt utilization at the cathode than standard Pt/carbon black materials. This technique is referred to as the 'fast multilayer' technique. The same technique was used in a previous study by Zils et al. to manufacture electrodes with carbon black material and Nafion layers, which were then compared to an airbrushed MEA with the same catalyst composition. ${ }^{[21]}$ The two different MEAs were characterized by focused ion beam tomography. The FIB measurements showed a much more homogenous electrode with a small average pore size for the multilayer MEA than the airbrushed MEA. Single-cell tests revealed a two times higher Pt utilization for the MEA prepared by the new technique. Thus, the new processing strategy already showed its suitability as a fast and easy method for fuel cell electrode preparation.

In this study the use of the alternative support material ITO and its incorporation into an advanced electrode structure is demonstrated and will give a first impression of how oxide nanoparticles can be assembled in a fuel cell electrode. The obtained results will bridge the gap between the previous results of electrochemical studies and the performance as catalyst material in a real fuel cell environment.

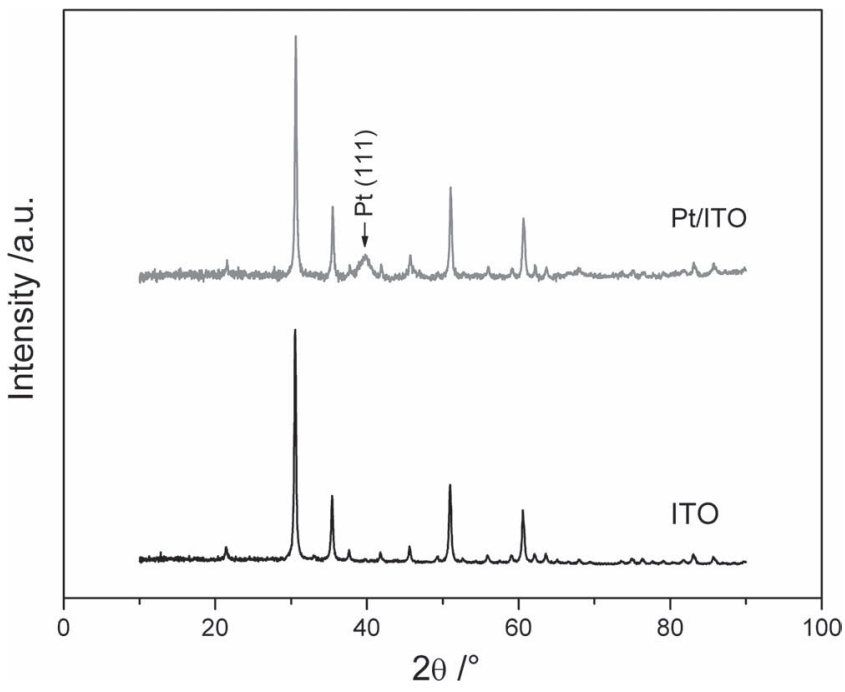

Figure 1. XRD pattern of ITO nanoparticles (Sigma-Aldrich) and Pt decorated ITO (with $\mathrm{Pt}(111)$ reflection marked by an arrow).

\section{Results and Discussion}

Pt nanoparticles on indium tin oxide nanoparticles have been considered as possible fuel cell catalyst materials. As already mentioned, previous studies by Chhina et al. ${ }^{[16]}$ and Park et al. ${ }^{[17]}$ showed the applicability as support material in cyclic voltammetry measurements due to the high oxidation stability of ITO catalyst. However, tests in a real fuel cell environment are still lacking. This study shows first results of embedded Pt/ ITO nanoparticles as catalyst for the ORR.

The reduction reaction of $\mathrm{PtCl}_{4}$ with $\mathrm{NaBH}_{4}$ leads to Pt nanoparticles onto the indium tin oxide support and the XRD pattern of Pt/ITO can be seen in Figure 1. The characteristic (111) reflection (marked by an arrow) of the fcc Pt at around $40^{\circ}$ is clearly visible. The other reflections are masked by the background of the ITO reflections, because of the low weight ratio of platinum to ITO. According to the supplier specification, the ITO nanoparticles have a particle size smaller than $50 \mathrm{~nm}$, which is verified by a Rietveld refinement of the obtained XRD pattern of ITO, giving a calculated particle size of $18 \mathrm{~nm}$. The Pt particles sizes are also derived from the Rietveld refinement on the obtained XRD pattern. The average Pt particles size is $2.4 \mathrm{~nm}$.

After the successful deposition of Pt on ITO the effect of electrode structure on the fuel cell performance is studied. The assembly of Pt/ITO with $20 \mathrm{wt} \%$ Nafion ionomer in the electrode showed no performance at all. This could be attributed to the very dense electrode structure formed by the nanosized support and the ionomer, preventing the desired gas transport. To enhance the porosity of the electrode network, another structure is introduced to obtain optimum conditions for a sufficient gas transport and simultaneously an adequate electron and proton conductivity. A suitable electrode structure has been found by the incorporation of Pt/ITO catalyst into a multi-walled carbon nanotubes (MWCNTs) network (coated with Nafion). The nanotube network has the advantage to be highly electron conductive and the ionomer coating ensures the proton conductive 


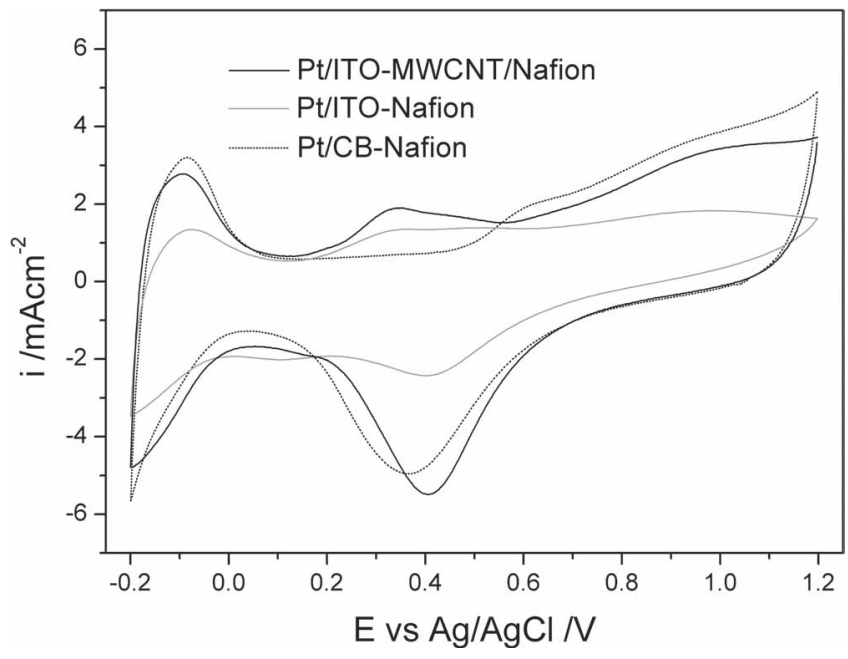

Figure 2. Cyclic voltammograms of Pt/CB-Nafion, Pt/ITO-Nafion, and a bilayer of Pt/ITO and MWCNT/Nafion. Data were recorded in $0.1 \mathrm{M} \mathrm{per-}$ chloric acid at $25^{\circ} \mathrm{C}$ and a sweep rate of $50 \mathrm{mV} \mathrm{s}^{-1}$.

character of the electrode. The catalytic active species Pt on ITO is embedded into the structure during the preparation process.

First characterizations of the proposed system have been done by cyclic voltammetry (CV). First, the prepared Pt/ITO catalyst was mixed with Nafion ${ }^{\circledR}$ ionomer and cycled between $-0.2-1.2 \mathrm{~V}$ vs. Ag/AgCl reference electrode. Secondly, the multilayer system was mimicked in its simplest way by depositing one layer of Pt/ITO and one layer of MWCNT/Nafion ${ }^{\circledR}$ on the glassy carbon electrode to perform a CV measurement. The corresponding cyclic voltammograms can be seen in Figure 2. The Pt/ITO catalyst alone showed low hydrogen adsorption and oxygen desorption (reduction) features. This could be attributed to the low conductivity of the ITO support and the poor accessibility of the Pt nanoparticles by the electrolyte within the catalyst layer. The coating of a Pt/ITO layer by a film of MWCNT/ Nafion significantly improved the electrochemical activity. A tremendous increase in the hydrogen adsorption/desorption $\left(\mathrm{H}_{\mathrm{ad} / \mathrm{des}}\right)$ and oxygen adsorption/desorption $\left(\mathrm{O}_{\mathrm{ad} / \mathrm{des}}\right)$ characteristics is observable for Pt/ITO-MWCNT/Nafion compared to Pt/ITO-Nafion without MWCNTs. The change arises from the higher electrical conductivity due to the nanotube network and the better accessibility of reactants due to the more porous structure. The single voltammograms can be compared by the calculation of the electrochemical active surface area (ECSA) of Pt of each catalyst. Therefore, the double-layer capacitance is subtracted from the $\mathrm{H}_{\text {ads }}$ peak and the resulting area under the peak is integrated. The average peak area corresponds to the total charge consumed by the Pt surface. The ECSA is then obtained by Equation 1.

$$
\mathrm{ECSA}=\frac{\mathrm{H}_{\mathrm{ads}}}{210 \mu \mathrm{Ccm}^{-2} \cdot \text { Ptloading }}
$$

The standard charge of $210 \mu \mathrm{C}$ correlates with the coverage of one $\mathrm{cm}^{2}$ surface area of three basal Pt planes. For the performed CV experiments, the ECSA of Pt/ITO/Nafion catalyst is $5.3 \mathrm{~m}^{2} \mathrm{~g}^{-1}$ and the ECSA of Pt/ITO-MWCNT/Nafion is $14.1 \mathrm{~m}^{2} \mathrm{~g}^{-1}$. As reference system Pt/carbon black with Nafion

\section{Anode Cathode}

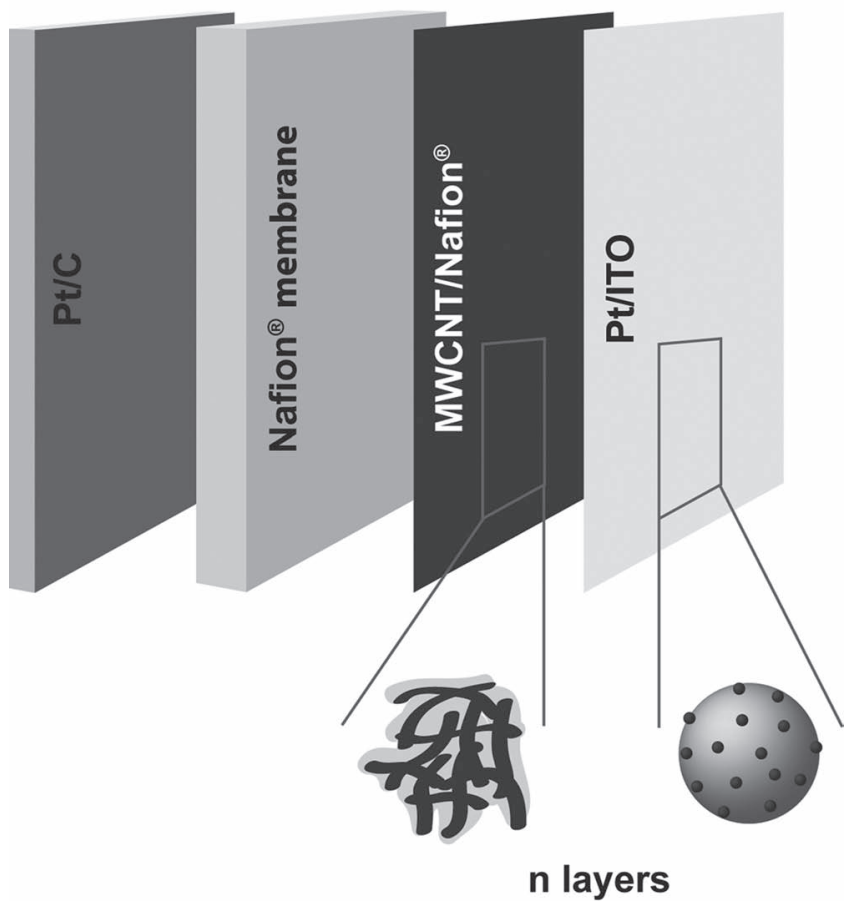

Figure 3. Schematic view of the multilayer MEA with Pt/ITO-MWCNT/ Nafion cathode.

has been tested under the same conditions, with an obtained ECSA of $16.4 \mathrm{~m}^{2} \mathrm{~g}^{-1}$. The incorporation of MWCNT into the oxide catalyst improved the ECSA characteristic. The 1D MWCNTs enhanced the porosity of the film and promoted a better accessibility of the Pt nanoparticles. The ECSA almost equaled the value for the standard Pt/CB catalyst with the advantage that ITO is more resistant to oxidation than carbon black. ${ }^{[16]}$ The replacement of Pt/CB by Pt/ITO can therefore be done without worsening the electrochemical performance. The low ECSA for the Pt/ITO-Nafion film supports the conclusion from the single-cell measurements that a pure Pt/ITO-Nafion electrode does not perform well electrochemically.

The schematic view of the multilayer electrode assembly is shown in Figure 3. The anode consists of a conventionally prepared Pt/CB electrode. The cathode was assembled in a different way allowing a tuning of the contact area of the functional components: the Pt nanoparticles, electrical conductive support, and the ionomer. The intersection of these components and the gas phase is called the triple-phase boundary (TPB). To improve the area of the TPB the components were sprayed successively for the ML-MEA. This assembly technique has been used in a previous study and showed its potential to manufacture electrodes with an increased contact between the individual parts and resulted in a 3D porous network for better reactant/product transport. ${ }^{[19]}$

After transferring this concept of Pt/ITO particles embedded into a nanotube network from the cyclic voltammetry test to an assembled electrode on a Nafion membrane, single cell measurements have been performed. The polarization curves 

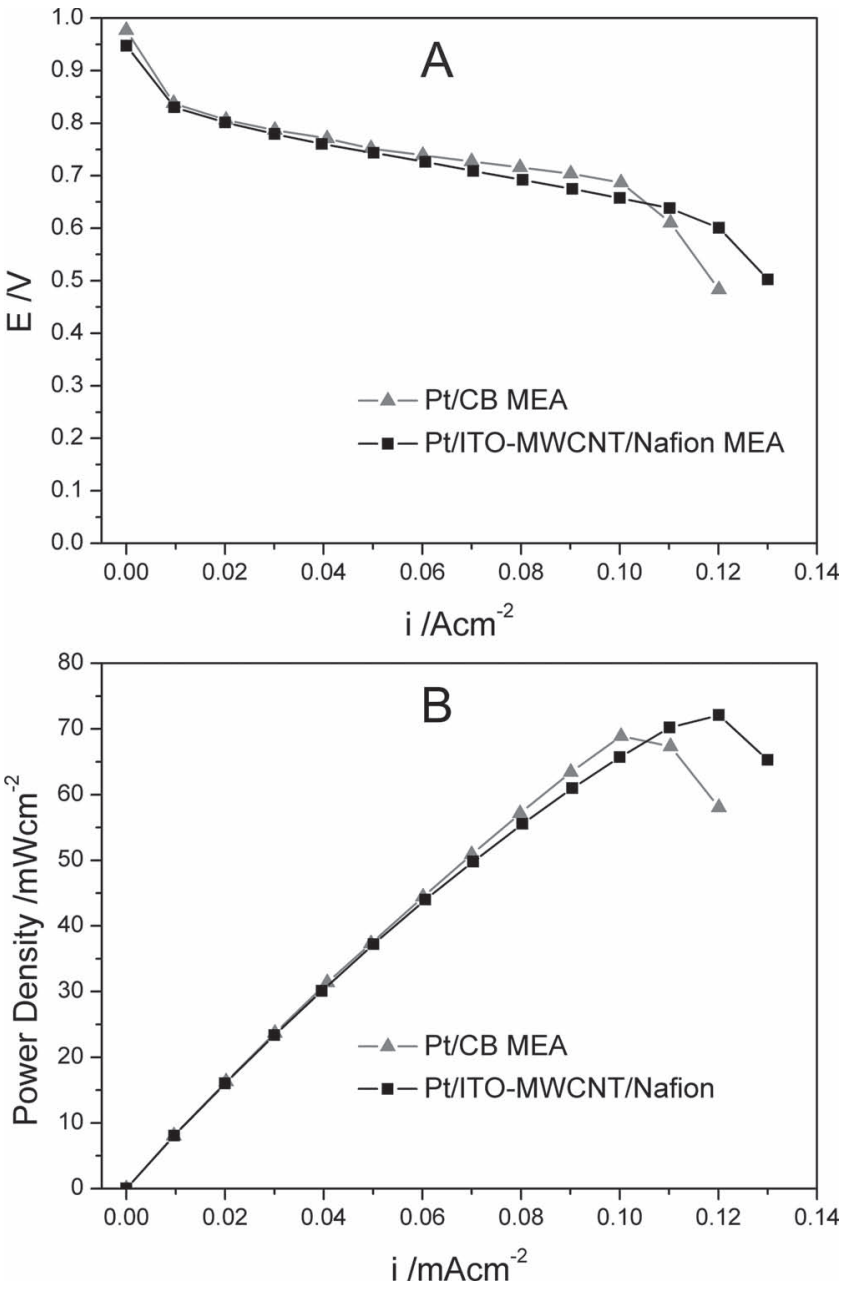

Figure 4. A) Polarization and B) power density curves of the ML-MEA ( $\square$ ) with a Pt loading at the cathode of $0.05 \mathrm{mg} \mathrm{cm}^{-2}$ and the standard Pt/CB MEA (匹) with a Pt loading of $0.04 \mathrm{mg} \mathrm{cm} \mathrm{cm}^{-2}$ operated at a cell temperature of $75{ }^{\circ} \mathrm{C}$, humidification temperature $80^{\circ} \mathrm{C}$, and a $\mathrm{H}_{2}$ flow rate of $200 \mathrm{~mL} \mathrm{~min}-1$ and $100 \mathrm{~mL} \mathrm{~min}^{-1}$ for $\mathrm{O}_{2}$, both at atmospheric pressure.

and the power density curves can be found in Figure 4 . The ML-MEA reached a maximum power density of $73 \mathrm{~mW} \mathrm{~cm} \mathrm{~cm}^{-2}$ at a current density of $0.12 \mathrm{~A} \mathrm{~cm}^{-2}$. The power density is comparable to the additionally measured standard Pt/CB MEA that possessed the same Pt loading on the cathode. The measured Pt/ITO-MWCNT/Nafion MEA had a Pt loading of $0.05 \mathrm{mg} \mathrm{cm}^{-2}$ on the cathode and the Pt/CB MEA a loading of $0.04 \mathrm{mg} \mathrm{cm}^{-2}$, respectively. The loading of the anode was kept the same for both MEAs. Starting with the maximum power density and the Pt loading of the cathode, the Pt utilization can be calculated. The Pt utilization for the ML MEA is $1468 \mathrm{~W} \mathrm{~g}_{(\mathrm{Pt})}{ }^{-1}$ and $1723 \mathrm{~W} \mathrm{~g}_{(\mathrm{Pt})}{ }^{-1}$ for the standard Pt/CB cathode of the standard MEA. Hence, the two Pt utilization values are located within the same range and reflect the results from the CV experiments, where both systems had almost the same ECSA. It should be noted that the parameters for the single-cell test were kept constant for both MEAs and were not adjusted to the special needs of each system. Therefore, the performance might be slightly different by optimizing the parameters for each MEA. It is remarkable that both MEAs show almost the same performance while possessing two completely different support morphologies. The spherical carbon black particles are in the micrometer range with micro- and macropores, whereas the ITO particles are in the nanometer range. The surface area of carbon black peaked around $200 \mathrm{~m}^{2} \mathrm{~g}^{-1[22]}$ and is therefore much higher compared to ITO $\left(27 \mathrm{~m}^{2} \mathrm{~g}^{-1}\right.$ according to the supplier). High surface areas are needed for a highly disperse deposition of noble metal particles. The disadvantage of low surface areas of oxide particles are usually circumvented by decreasing the size of the particles resulting in higher surface areas. The challenge now is to assemble a porous electrode structure by using the nanosized oxide catalyst particles. The herein proposed electrode preparation delivered such a network structure and the structural investigations can be seen in Figure 5. The SEM micrographs have been taken after the single cell measurements. The MEA was cut by a scalpel along the middle axis to get an insight into the electrode's morphology.

The SEM micrograph in Figure 5A shows a cross-sectional/top-view of the edge of the ML electrode, indicating a rough surface. The roughness might derive from clustering of Pt/ITO and MWCNTs during the spraying process. On the cross-sectional view in Figure $5 \mathrm{~B}$ the electrode thickness can be measured by taking intersections corresponding to the electrode size. The thickness was measured to be $5.4 \mu \mathrm{m}$. The low and high magnification micrographs $\mathrm{C}$ and $\mathrm{D}$ of the electrode surface indicate the mentioned network structure. In Figure 5D single nanotube fibers are visible and the structure seems to be very porous.

\section{Conclusion}

This study showed a simple preparation technique for advanced electrode structures which succeeded in incorporating Pt/ITO into a porous nanotube network. The architecture favored the gas permeability and a better accessibility of the active sites of Pt was obtained. SEM and electrochemical measurements verified this assumption. As far as we know that is the first time that Pt/ITO is used in a real fuel cell environment. The catalyst showed a performance and Pt utilization comparable to a standard Pt/CB MEA. Because of ITO's better oxidation resistance, it might be a possible candidate for replacing carbon black without a loss in performance. The conductivity within the electrode was provided by a small amount of highly conductive MWCNTs. It should be mentioned that the amount of nanotubes was also reduced to a minimum compared to electrodes using only Pt/carbon nanotubes. This might open the way to the manufacturing of costefficient and easily prepared fuel cell electrodes. Before, the electrode has to prove its stability in long term tests, which is not a part of this work.

\section{Experimental Section}

All chemicals were purchased from Sigma-Aldrich and used as received. Indium tin oxide nanoparticles $(<50 \mathrm{~nm})$, multi-walled carbon nanotubes, 

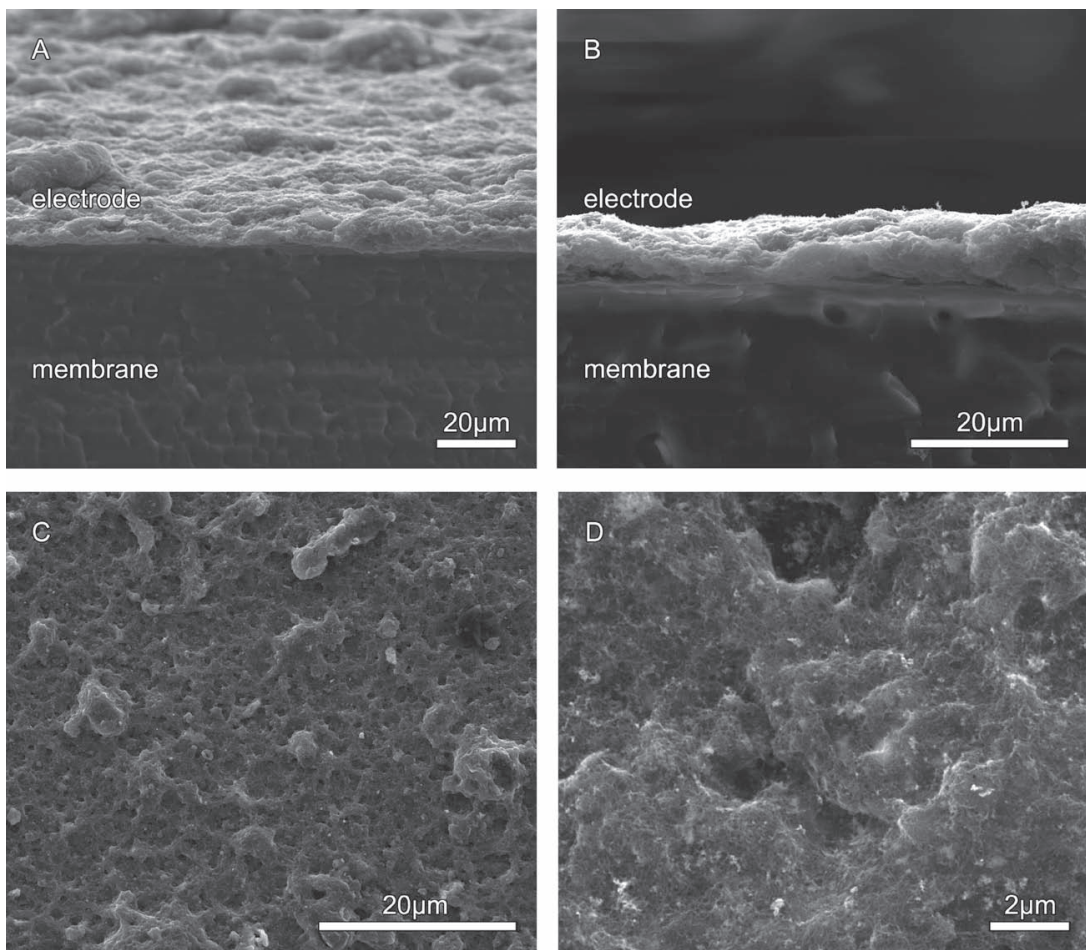

Figure 5. SEM micrographs of the multilayered cathode A) cross-sectional and top view B) cross-sectional view perpendicular to the electrode assembly direction C) low magnification top view and D) high magnification top view.

and Nafion 117 solution (5\% Nafion 1100 in a mixture of lower aliphatic alcohols and water) were also purchased from Sigma-Aldrich.

Decoration of ITO Nanoparticles: ITO nanoparticles (NP) were decorated with $\mathrm{Pt} \mathrm{NP}$ after a reduction of $\mathrm{PtCl}_{4}$ precursor by sodium borohydride $\left(\mathrm{NaBH}_{4}\right)$. ITO NP $(120 \mathrm{mg})$ and $\mathrm{PtCl}_{4}(51.8 \mathrm{mg}, 99.99+\%)$ were dispersed in ultrapure (MilliQ: MQ) water $(20 \mathrm{~mL})$ by strong ultrasonication with a disintegrator. Therefore, the amount of $\mathrm{PtCl}_{4}$ corresponds to a Pt loading of $20 \mathrm{wt} \%$ on the ITO. After a homogeneous dispersion was obtained the sonication was stopped for a few seconds and a solution of $\mathrm{NaBH}_{4}(51.8 \mathrm{mg}$, granules, $99.99 \%)$ in $\mathrm{MQ}(10 \mathrm{~mL})$ was added quickly to the ITO-PtCl . The dispersion turned black immediately. Strong ultrasonication was applied right after the addition of the reducing agent to prevent $\mathrm{Pt}$ nanoparticle agglomeration during their formation. Afterwards, the solution was diluted with deionized water, filtered through a $0.02 \mu \mathrm{m}$ Anopore Inorganic Membrane (Whatman) and dried at $30^{\circ} \mathrm{C}$ under vacuum

Functionalization of the Nanotubes: The MWCNT were treated in concentrated acids in order to functionalize their surface with carboxylic, carbonylic, and hydroxylic groups and to remove remaining amorphous carbon species. Therefore, MWCNT $(20 \mathrm{mg})$ were dispersed in $\mathrm{HNO}_{3}$ (6 mL, p.a., 65\%) and $\mathrm{H}_{2} \mathrm{SO}_{4}(6 \mathrm{~mL}$, ACS reagent, 95-98\%) and ultrasonicated for $30 \mathrm{~min}$. After the functionalization, the nanotubes were diluted with copious amounts of $\mathrm{MQ}$, filtered with a $0.45 \mu \mathrm{m}$ Polycarbonate Track-Etch Membrane, rinsed with $\mathrm{MQ}$ water and dispersed in a solution of ethanol and $\mathrm{MQ}(5 \mathrm{~mL}, 80: 20$ by volume). A mixture of Nafion solution $(0.34 \mathrm{~mL})$ in ethanol/MQ $(5 \mathrm{~mL}, 80: 20)$ solution was prepared and homogenized by ultrasound. Then the MWCNT dispersion was added dropwise to the ionomer dispersion followed by adding of Pt/ITO (40 mg, $20 \mathrm{wt} \%$ Pt loading), which were dissolved in ethanol/MQ solution (10 mL, 80:20) before.

MEA Preparation: Polymer electrolyte membranes of Nafion 117 were purchased from Ion Power Inc., USA. The membranes were treated according to a standard procedure described elsewhere before being used for further preparation. ${ }^{[23]}$
The membrane was mounted in a home built spraying plate with vacuum feature. The plate was heated up to $80{ }^{\circ} \mathrm{C}$ and a solution of $\mathrm{Pt}$ on Vulcan-XC72 (80 mg, HiSPEC 3000, Johnson Matthey), Nafion 117 solution $(0.4 \mathrm{~mL})$, MQ $(3.6 \mathrm{~mL})$, and ethanol $(12 \mathrm{~mL})$ was coated onto the membrane by EcoSpray containers (Labo Chimie France). The cathode was assembled by alternating layers of Pt/ITO and MWCNT/Nafion. The two solutions were sprayed with two separate EcoSpray containers and the composition was the same as for the mixed MEA. The preparation technique is described in detail elsewhere. [19] The MEA is referred to as multilayer MEA (ML-MEA).

For comparison, a second MEA was sprayed, consisting of a standard Pt/CB anode with the same loading used before and a Pt/CB cathode, with a Pt loading and Nafion content equal to the $\mathrm{Pt} / \mathrm{ITO}$ cathode. Therefore, Pt/CB (40 mg, HiSPEC $3000)$, Nafion solution $(0.229 \mathrm{~mL}), \mathrm{MQ}(3.8 \mathrm{~mL})$ ethanol $(12 \mathrm{~mL})$ were dispersed and sprayed under the same conditions. The active electrode area for all MEAs is $10 \mathrm{~cm}^{2}$.

MEA and Catalyst Characterization: The ITO supported Pt NP were characterized by X-ray diffraction (XRD) and transmission electron microscopy (TEM). The XRD was carried out with a $X$ 'Pert-Pro diffractometer in reflection geometry operating with $\mathrm{Cu} \mathrm{K}_{\alpha 1}$ and $\mathrm{K}_{\alpha 2}$ radiation $(\lambda=$ $1.54060 \AA$ ). Rietveld refinement was used to obtain the FWHM of the XRD patterns and to calculate the particle sizes of ITO and Pt.

Scanning electron microscopy (SEM) was applied for the characterization of the MEAs. Topview and cross-sectional investigations on the Pt/ITO electrode were carried out on a FEI Quanta 200 FEG, equipped with a field emission gun operating at $15 \mathrm{kV}$.

Cyclic Voltammetry: Cyclic voltammograms (CVs) were measured with a Gamry Reference 600 potentiostat (USA) in a standard glass threecompartment electrochemical cell (Bio-Logic SAS), with a glassy carbon working electrode ( $\varnothing 3 \mathrm{~mm}$, BASi Instruments, USA), a Pt wire serving as counter electrode, and an $\mathrm{Ag} / \mathrm{AgCl}(\mathrm{NaCl}(3 \mathrm{M})$ electrolyte) reference electrode (ASL, Japan). The potential between the working electrode (WE) and reference electrode was cycled 10 times between $-0.2-1.2 \mathrm{~V}$ with a sweep rate of $50 \mathrm{mV} \mathrm{s}{ }^{-1}$. The electrolyte was prepared with $\mathrm{MQ}$ water and $\mathrm{HClO}_{4}$ (ACS reagent 70\%) at a concentration of $0.1 \mathrm{~m}$. The electrolyte was purged for $5 \mathrm{~min}$ with Ar. Overall three different catalysts have been measured. Three different catalyst dispersions have been prepared. First, a dispersion of Pt/CB (15 mg, HiSPEC 3000) is mixed with Nafion solution $(86 \mu \mathrm{L})$ and $\mathrm{MQ}(1.5 \mathrm{~mL})$. Secondly, Pt/ITO (15 mg) was dispersed in Nafion $(86 \mu \mathrm{L})$, and $\mathrm{MQ}(1.5 \mathrm{~mL})$. Finally, MWCNT $(7.5 \mathrm{mg})$ are dispersed in Nafion solution $(129 \mu \mathrm{L})$ and MQ $(1.5 \mathrm{~mL})$, and Pt/ITO $(15 \mathrm{mg})$ are dispersed in $\mathrm{MQ}(1.5 \mathrm{~mL})$. For the first two dispersions, the ink $(7.5 \mu \mathrm{L})$ is transferred with a micropipette to the working electrode and the solvent was allowed to evaporate. The last catalyst was transferred on the WE in a layer-by-layer manner. As first layer, the Pt/ITO dispersion $(7.5 \mu \mathrm{L})$ was dropped onto the WE and dried, and coated with the MWCNT/Nafion dispersion $(7.5 \mu \mathrm{L})$. The third approach was used to mimic the multilayer approach of the cathode layer. After each experiment the WE was cleaned and polished with $1 \mu \mathrm{m}$ diamond paste to remove remaining surface oxides. No correction for the uncompensated resistance is applied for the experimental data.

Single-Cell Tests: Polarization curves of the MEA were collected with a FuelCon Evaluator C50 test bench (FuelCon AG, Germany), in which the Pt/ITO-MWCNT/Nafion electrode was used as cathode and the standard $\mathrm{Pt} / \mathrm{CB}$ electrode as anode. The MEA was placed between two gas diffusion layers (Toray Carbon Paper TGP-H-090, 60 wt\% wet proofing) and sealed with silicon coated fiberglass gaskets. Humidified 
hydrogen was fed to the anode with a flow rate of $200 \mathrm{~mL} \mathrm{~min}{ }^{-1}$ and high-purity oxygen was provided to the cathode at a flow rate of $100 \mathrm{~mL} \mathrm{~min}-1$. The anode/cathode gas humidifiers were set to $80^{\circ} \mathrm{C}$ and the cell temperature to $75^{\circ} \mathrm{C}$. The MEA was conditioned at a low current overnight. The polarization curves were recorded automatically with the software package FuelWork by increasing the current in steps of $0.1 \mathrm{~A}$ after a steady state potential has been reached. The standard Pt/CB MEA has been tested in the same manner to ensure a comparability of the two MEAs.

\section{Acknowledgements}

The present project is supported by the National Research Fund, Luxembourg.

Received: November 23, 2011

Published online: March 14, 2012

[1] Ryan O'Hayre, Suk-Won Cha, Whitney Colella, Fritz B. Prinz, Fuel Cell Fundamentals, John Wiley \& Sons, New York, USA 2009.

[2] K. H. Kangasniemi, D. A. Condit, T. D. Jarvi, J. Electrochem. Soc. 2004, 151, E125

[3] F. Ettingshausen, J. Kleemann, A. Marcu, G. Toth, H. Fuess, C. Roth, Fuel Cells 2011, 11, 238.

[4] L. M. Roen, C. H. Paik, T. D. Jarvic, Electrochem. Solid State Lett. 2004, 7, A19.

[5] S. Guo, E. Wang, Nano Today 2011, 6, 240.

[6] E. Antolini, E. R. Gonzalez, Appl. Catal., A 2009, 365, 1.

[7] a) E. Antolini, E. R. Gonzalez, Solid State lonics 2009, 180, 746; b) Y. Y. Shao, J. Liu, Y. Wang, Y. H. Lin, J. Mater. Chem. 2009, 19, 46.
www.MaterialsViews.com

[8] a) K. Lasch, L. Jorissen, J. Garche, J. Power Sources 1999, 84, 225; b) E. J. McLeod, V. I. Birss, Electrochim. Acta 2005, 51, 684.

[9] O. Savadogo, P. Beck, J. Electrochem. Soc. 1996, 143, 3842.

[10] a) S. Y. Huang, P. Ganesan, B. N. Popov, Appl. Catal., B 2010, 96, 224; b) N. Rajalakshmi, N. Lakshmi, K. S. Dhathathreyan, Int. J. Hydrogen Energy 2008, 33, 7521.

[11] a) A. Masao, S. Noda, F. Takasaki, K. Ito, K. Sasaki, Electrochem. Solid State Lett. 2009, 12, B119; b) K. Kakinuma, M. Uchida, T. Kamino, H. Uchida, M. Watanabe, Electrochim. Acta 2011, 56, 2881; c) P. Zhang, S. Y. Huang, B. N. Popov, J. Electrochem. Soc. 2010, 157, B1163.

[12] E. Fortunato, D. Ginley, H. Hosono, D. C. Paine, Mat. Res. Bull. 2007, 32, 242.

[13] M. Grundmann, H. Frenzel, A. Lajn, M. Lorenz, F. Schein, H. von Wenckstern, Phys. Status Solidi A 2010, 207, 1437.

[14] J. Suffner, S. Kaserer, H. Hahn, C. Roth, F. Ettingshausen, Adv. Energy Mat. 2011, 1, 648.

[15] P. Parent, H. Dexpert, G. Tourillon, J. M. Grimal, J. Electrochem. Soc. 1992, 139, 276.

[16] H. Chhina, S. Campbell, O. Kesler, J. Power Sources 2006, 161, 893.

[17] I.-S. Park, E. Lee, A. Manthiram, J. Electrochem. Soc. 2010, 157, B251.

[18] R. O'Hayre, D. M. Barnett, F. B. Prinz, J. Electrochem. Soc. 2005, 152, A439.

[19] A. Wolz, S. Zils, M. Michel, C. Roth, J. Power Sources 2010, 195, 8162.

[20] S. Zils, A. Wolz, M. Michel, C. Roth, ECS Trans. 2010, 28, 33.

[21] S. Zils, M. Timpel, T. Arlt, A. Wolz, I. Manke, C. Roth, Fuel Cells 2010, 10, 966.

[22] E. Antolini, Appl. Catal., B 2009, 88, 1.

[23]M. Michel, F. Ettingshausen, F. Scheiba, A. Wolz, C. Roth, Phys. Chem. Chem. Phys. 2008, 10, 3796. 